\title{
The Effects of a Chinese and Cuban Music Programme on the Cultural Understanding of Elementary Children
}

\author{
Lily Chen-Hafteck \\ UCLA Herb Alpert School of Music. \\ University of California, Los Angeles, USA \\ e-mail: lhafteck@ucla.edu
}

Published online: 17 October 2018

Cite this article (APA): Chen-Hafteck, L. (2018). The effects of a Chinese and Cuban music programme on the cultural understanding of elementary children. Malaysian Journal of Music, 7 , 117-133.

\begin{abstract}
This study aims to examine whether the American elementary students increase their cultural understanding after a six-week multicultural music programme on China and Cuba, considering factors of age, gender and learning needs. The use of Edwards' (1994) levels of cultural understanding as a research tool and the way in which this approach can motivate children learning were examined. Participants were 110 second and fifth graders of two schools in New Jersey. Interviews were administered before and after the programme and classroom observations were conducted. Data indicated that such multicultural music programme has increased children's cultural understanding and reduce their stereotypes on other people. Different levels of cultural understanding have been demonstrated. It was easy for children to achieve the basic level (i.e. Level 1: Knowledge) but it became more and more difficult as the levels proceed (i.e. Levels 2-4: Awareness, Sensitivity and Valuing). Therefore, multicultural music education can serve important educational goal of increasing cultural understanding, motivate student learning and provide an interdisciplinary education to students.
\end{abstract}

Keywords: China, Cuba, cultural understanding, multicultural music education

\section{Introduction}

\section{Need for Multicultural Education due to Diverse Student Population}

Today, student population in most of the American classrooms is often diverse in cultures, languages, abilities, and so on. However, most of the U.S. public school teachers are white who grew up in middle-class communities (Gay, Dingus \& Jackson, 2003) Although the number of teachers from minority groups has increased in recent 
years, the gap between the percentage of minority students and minority teachers continues to persist in the USA (Ingersoll, Merrill \& Stuckey, 2014). Therefore, most teachers are not prepared to teach diverse students, and need to learn about culturally responsive pedagogy (Ladson-Billings, 2004; Vavrus, 2002). Culturally responsive teaching acknowledges the legitimacy of the cultural heritages of different ethnic groups that affect students' dispositions, attitudes and approaches to learning. It teaches students to know and praise their own as well as others' cultural heritages (Gay, 2010). Otherwise, we can easily fall into the prejudices of the 'culture of poverty', the overgeneralisation that poor people share certain predictable values and behaviours such as being unmotivated, having weak work ethics, parents not being involved in children's education, being linguistically deficient, abusing drugs and alcohol, which are not valid in most cases (Gorski, 2008).

A lot of our students' ethno-cultural attitudes and believes have been acquired early in life and they are usually deeply rooted. Marks \& Coll (2009) found that American children already show social awareness by labelling racial groups at the age of three. By the ages of four and five, they start to develop the ability to identify oneself from others. At the ages of seven or eight, children have developed stable and consistent social identity. Between ages six to twelve, children are often trying to make sense of who they are in terms of race, ethnicity, and culture. Thus, it is important to provide a multicultural education early in life so that they can understand and appreciate the people of diverse cultural origins who live around them at these early formative years.

Multicultural education, which is in line with culturally responsive teaching, promotes equity in educational opportunities for students from diverse groups. However, it may not achieve its goal if the teacher thinks that it is simply content integration (Banks, 2004). Teachers need to adjust their approaches to achieve other dimensions including knowledge construction, equity pedagogy, prejudice reduction and empowering school culture and social structure that can move education to a higher level in the learning and understanding of cultures.

\section{Multicultural Music Education and Cultural Understanding}

Music both expresses and is influenced by the culture from which it comes. The rich cultural knowledge within traditional music and songs makes them useful resources for teaching children about their own culture and that of others. Elliott (1989) indicated that "a dynamic multicultural music curriculum offers the possibility of developing appreciations and new behaviour patterns not only in relation to world musics, but also in relation to world peoples." (p.18) Multicultural approach to music learning is important in American schools because it reflects the cultural diversity of the world and of the USA by promoting a music curriculum representing musical experiences of a variety of ethnic-cultures (Anderson and Campbell, 2010). Legette (2003) supported this idea, advocating for the need of more multicultural training in both the pre-service and in-service teacher education as the student population becomes more and more culturally diverse.

There is a large body of research in neuroscience, psychology of music, cultural musicology, sociology, anthropology of music suggesting that music has the capacity to promote empathy and social/ cultural understanding (Clarke, DeNora \& Vuoskoski, 
2015). Music as a tool that fosters social bonding and group cohesion has been demonstrated by Kirschner and Tomasello (2010). They found among the four-year-old children that joint music-making increased subsequent spontaneous cooperative and helpful behaviour. They argued that music making, including joint singing and dancing, encourages the participants to keep a constant audio-visual representation of the collective intention, which is to share the goal of vocalising and moving together in time. This can satisfy the intrinsic human desire to share emotions, experiences and activities with others, and thus ultimately increase prosocial in-group behaviour and cooperation. Therefore, the power of music in promoting our social well-being is demonstrated.

There are a number of research studies that showed positive effects of multicultural music programmes on children's attitude towards foreign cultures. Edwards (1994) investigated the impact of four instructional approaches utilising American Indian music on $4^{\text {th }}$ grade students' attitude towards American Indian culture and music - large-group lessons with authentic instruments, an American Indian guest artist, use of authentic instruments in small-group learning centres, and the use of nonauthentic instruments in small-group learning centres. A 6-week instructional period that contained 12 lessons was presented to four groups of children with the four teaching approaches plus a control group with no treatment. Significant difference was found between the experimental groups and the control group. It was found that the children were capable of the four levels of cultural understanding, ranging from a biased view (ethnocentrism) to unbiased view (cultural valuing) on a continuum.

1. Instructional knowledge, skills \& attitudes: Children acquire learning of the instructional materials;

2. Cultural awareness: Children become aware of the differences and similarities of various cultures;

3. Cultural sensitivity: Children's feeling and affect are involved; and

4. Cultural valuing: An unbiased view of the value of another culture.

The first level occurs when students become more knowledgeable of the culture, which are learning outcomes resulting from the instructions. Then, students' views become gradually less biased with the second level where they increase their awareness of other cultures that may be different and similar. Further up the scale of decreasing biases, the third level involves emotions in addition to the cognitive understanding of the culture while the fourth and final level is an unbiased view when students see the value of the culture. Edwards concluded from her data that children can unlearn previously-held cultural biases through instruction and develop cultural sensitivities that extend beyond knowledge.

In another study, Nam (2007) investigated children's perceptions about, attitudes towards and understandings of cultures other than their own as they encountered music from various cultures during their general music classes. The music lessons in two elementary schools were observed during three months. One group worked on African drumming whereas the other group worked on listening examples from a variety of cultures. Questionnaires and interviews were administered before and after the observation period. Positive attitudes towards multicultural music instruction 
were found. Using Edwards' levels of cultural understanding as the basis of her analysis, she found that most children demonstrated cultural awareness and sensitivity while few demonstrated cultural valuing. She contended that although embedding multicultural music into the curriculum may aim at minimising biased views, a 'supermarket approach' where children were exposed to a lot of different cultures may limit cultural understanding. Therefore, Nam recommended a more in-depth and carefully guided study of few cultures in order to develop cultural understanding more effectively.

$\mathrm{Tu}$ (2009) examined the effect of a Chinese music curriculum on cultural attitudes towards the Chinese people, improving tonal discrimination skills, singing accuracy of tonal patterns and accuracy of singing Chinese lyrics. Participants were third-, fourth-, and fifth-grade students who received daily exposure of 10-minute Chinese music lesson during 10 weeks. Standardised tests including 'Children's Attitudes toward Chinese' (CATC), 'Intermediate Measures of Music Audition - Tonal' (IMMA), 'Tonal Pattern Performance Measure' (TPPM) were used for measurement at the pre- and post-tests. It was found that children's attitudes toward Chinese people and tonal pattern singing accuracy were improved, but not tonal discrimination skills. Accuracy of the Chinese lyrics was over $70 \%$

Sousa, Neto and Mullet (2005) has conducted a study in Portugal where its largest group of foreign immigrants come from Cape Verde, a former Portuguese colony in Africa, and there is evidence of pro-white-skinned/ anti-dark-skinned stereotyping. Therefore, the researchers investigated whether Portuguese children would change their attitudes towards Cape-Verdeans after learning the songs from Cape Verde. Eighteen units of Cape-Verdean music instruction were provided to 193 children aged 7-10 years. Pre-test and post-test using Preschool Racial Attitude Measure II (PRAM II) were administered to measure children's racial attitude. Results suggested that there was a reduction of stereotyping of Cape Verdeans in the experimental group, but this was found among the 9- and 10-year-olds, not the 7- and 8-year-olds. Therefore, age difference was shown to be a significant factor in this study.

I, (Chen-Hafteck, 2007a) have examined the effects of an interdisciplinary programme on Chinese music and culture. A programme based on the sociocultural approach to multicultural music education whereby students learn about the music together with its sociocultural context was introduced to 250 fifth- and sixth-grade children in three schools in New York, USA. Findings showed that whether multicultural music education experience can lead to positive cultural understanding and attitude depends on many factors, including teachers' attitude, teaching approach, and the students' learning environment. A flexible student-centred curriculum using the sociocultural approach can enhance an increase in cultural and musical knowledge, learning motivation, positive attitude towards people from other cultures, and selfconfidence for students from the minority cultures. Effects were strong among students studying in a multicultural environment than those in a monocultural setting.

From the various research studies discussed above, it is important to note that multicultural music lessons need to be well-designed with varied activities such as presenting information on the cultures, singing songs, dancing, moving and creating. In this way, they can provide a comprehensive learning experience that enhances students' cognitive, social, physical and emotional development (Ilari et al., 2013). It is also a 
good example of interdisciplinary approach to education, integrating the arts and social studies.

In summary, there is strong argument supporting the positive influences of learning multicultural music on children's understanding and appreciation of people from cultures other their own. The notion of cultural understanding has been expanded in the $21^{\text {st }}$ century competencies (Soland, Hamilton \& Stecher, 2013) as developed by international educators. Global awareness is one of the interpersonal competencies, demonstrated when a student feels empathy for people from different cultural backgrounds, and when he/ she shows an understanding of the interpersonal nature of people, institutions and systems. Thus, this adds another dimension to Edward's (1994) levels of cultural understanding, which goes beyond unbiased view of other people.

\section{Rationale for Current Study}

However, research studies in this topic are still lagging behind. It seems that the relationship between learning multicultural music and cultural understanding is a complex issue. Such relationship can be affected by numerous factors. First and foremost, it is the assessment on children's cultural understanding. It is questionable whether it can be measured through standardised psychological tests (Sousa et al, 2005; $\mathrm{Tu}, 2009$ ) or observed through qualitative methodology (Edwards, 1994; Nam 2007; [author's name removed]). Then, it is further complicated by the teachers' attitude and teaching approaches, that can yield different results (Nam, 2007; [author's name removed]). In addition, the environment where the students live in, whether they are in touch with people from other cultures, can also influence the relationship between the multicultural music programme and cultural understanding.

Given the complexity of the issue, the present study has been designed to follow up the previous study [author's name removed] by collecting more first-hand information from the children. In the 2007 study, data have been collected through teachers and administrators. In the present study, personal interviews with the participating children and researchers' observations of the lessons were the main tool in providing data that may deepen our understanding of the issue. As a follow-up study, the teaching materials on Chinese music and culture developed in the previous New York study were used again. In addition, new materials on Cuban music and culture were developed and taught, because in New Jersey where this study took place, there is a large population of Cuban immigrants and enhancing cultural understanding of Cuban people will be beneficial to children living there. This can also show whether the effects of Chinese music also exist with the music of a different culture.

\section{Objective}

The objective of the present study was to investigate whether a multicultural programme combining the study of music and culture from China and Cuba has any effects on the cultural understanding of these two cultures among elementary children in New Jersey, USA. Cultural understanding was examined with reference to Edwards' model (1994). 
It serves as an evaluation tool along the biased-unbiased continuum, to provide analysis as to whether children increase their understanding about the cultures.

The research questions of this study were:

1. Would the American elementary students increase their cultural understanding after a six-week multicultural music programme on China and Cuba?

2. If so, would this effect be different among elementary children of different ages, gender, and learning needs?

3. Are Edwards' (1994) levels of cultural understanding useful measurement for research study on cultural understanding?

4. In what way can lessons incorporating music from world cultures motivate children learning?

\section{Method}

\section{Design of the Study}

Six weekly lessons were taught by me (of Chinese origin) and a research-assistant (of Cuban origin) to 110 students from eight classes of $2^{\text {nd }}$ grade and $5^{\text {th }}$ grade children in two multicultural and co-educational public schools in New Jersey - two $2^{\text {nd }}$ and two $5^{\text {th }}$ grade classes (ages 6-7 and 10-11) from each school. A bilingual $2^{\text {nd }}$ grade class with Spanish-speaking children and a special education $5^{\text {th }}$ grade class with children being diagnosed as 'Learning Disabled' were included. School 1 has a majority of African American students and School 2 has a majority of Hispanic students. Student population in the public schools of the State of New Jersey is diverse. Purposive sampling has been used so that the effects of multicultural music education on elementary children of diverse population can be observed. The purpose was to look at whether there are changes in students of varied backgrounds before and after the multicultural music programme.

The 6 lessons covered the following topics, selected because their potential to enhance student understanding of the two cultures and to be learned through integrating music activities such as listening, moving, singing, dancing and playing instruments. Active music-making activities were designed so that students can be engaged in the learning processes. The enjoyment of these lessons was important to generate a positive experience among the participants.

1. History \& Geography of China and its people, integrated with an introduction to traditional folk songs and music

2. Chinese philosophies integrated with music for enlightenment/ meditation and images of traditional paintings

3. Chinese festivals integrated with festive music, which was preceded by an introduction to Chinese musical instruments

4. History \& geography of Cuba and its people, integrated with an introduction to traditional folk songs and music 
5. Everyday life of Cuban People: Street vendors and musicians; influence of African culture in Cuban music and dance; Cuban musical instruments

6. Cuban Festivals, Carnivals, its music and dance

\section{Data Collection}

Interviews were conducted with the participating children before and after the six lessons. They were asked to respond to a simple open-ended question: "What do you know about China/ Cuba and Chinese/ Cuban people?" The purpose was to find out what children had to say by themselves without directing them towards any preconceived subjects. Researcher often asked follow-up questions based on students' answers to lead the conversation into a deeper understanding of student thoughts. So although this is only one question, researcher made sure that the data was adequate in terms of length and depth, providing the data needed for learning about students' level of cultural understanding.

At first, the interviews happened during lunch break when the researcher called them one after another into a quiet room. However, this was very time-consuming and soon it became apparent that it was impossible to interview all the participating children in this way, given the limited amount of time. So the researcher had to interview the children in a nearby location such as a corner of the cafeteria or playground. Given the limitations in time and location, the researcher could only take written notes to record the interview data. In addition, all the lessons were video-recorded. Observational notes were taken based on the researchers' teaching experiences and video data. Both quantitative and qualitative data were collected and analysed, complementing each other.

\section{Data Analysis}

First, a score was generated from each interview by each child by counting the number of statements that reflect cultural understanding. The statements that are untrue cannot demonstrate cultural understanding were not counted. For instance, one of the children got mixed up between Chinese and Japanese languages, and said that the Chinese people say kinochiwa (which is Japanese) to greet each other. The zero scores, which indicated that the children did not give any answer, were also recorded. In addition, each statement was coded according to Edwards' (1994) four levels of cultural understandings that were adapted to this study because these levels were originally findings from a study, not a research tool. So I need to specify more clearly how they can be used for data analysis. The coding was based on the nature of the statements collected from the children: (1) Knowledge: Correct factual information; (2) Awareness: Comparison between self and others; (3) Sensitivity: Feelings for the others; and (4) Valuing: Unbiased value/ global view of self and others (see examples in Discussion section). While the numerical scores were used as the basis of comparison, the meanings of the texts from the interview data were also analysed to provide a more in-depth qualitative understanding into the quantitative data (as discussed later in the 'discussion section'). Furthermore, the observational notes taken after each lesson and after reviewing the video data, were analysed and provided insight into children's learning 
processes during the study. Finally, student's t-test with equal variance assumed was carried out in comparing the pre- and post-test interview data for China and Cuba respectively. Moreover, a one-way ANOVA was used looking at pre- to post- test pairwise score increases for China and Cuba separately, to determine if there were significant differences when categorising by grade (age), gender and class (varied learning needs). Each comparison was run as a separate one-way ANOVA test. The only significant findings were with class and grade with the CUBA students. For the statistical analysis, the total number of children considered was 82 . This was because 28 children were not available for both of the interviews.

\section{Results}

The pre- and post-test results $(n=82)$ clearly showed a significant difference in the children's increased responses before and after the programme both in their cultural understanding of China $(d f=162, \mathrm{t}=-7.17, p=2.49 \mathrm{e}-11)$ and Cuba $(d f=162, \mathrm{t}=-9.28, p$ $<2.2 \mathrm{e}-16$ ). Interestingly, a higher gain in cultural understanding has been found in Cuban music and culture as compared to Chinese music and culture, though this is not statistically significant (see Table 1 and Figure 1).

The majority of responses were under the first level of cultural understanding, with less under the second, even less under the third and rare under the fourth level (see Figure 2). This means that the higher the level of cultural understanding, the lower the number of responses that fell under the category.

No significant difference has been found across schools and gender for all data as well as grades and class of the China data. The only significant difference found was among the grades $(\mathrm{F}=4.001, d f=1, p=0.05)$ and classes $(\mathrm{F}=2.3842, d f=7, p=0.03)$ from the data of Cuba (see Tables 2-3 and Figure 3).

Table 1

Student's t-test with equal variance results on children's interview responses before and after the programme

\begin{tabular}{|c|c|c|c|c|}
\hline & Pre-test & Post-test & & \\
\hline & $M(S D)$ & $M(S D)$ & $t$ & $d f$ \\
\hline China & $2.65(1.96)$ & $5.24(3.04)$ & $-7.17 * * *$ & 162 \\
\hline Cuba & $1.20(1.82)$ & $5.23(3.53)$ & $-9.28 * * *$ & 162 \\
\hline
\end{tabular}

Note. $* * *=p \leq .001$ 


\section{Children's Interview Responses before and after the Program}

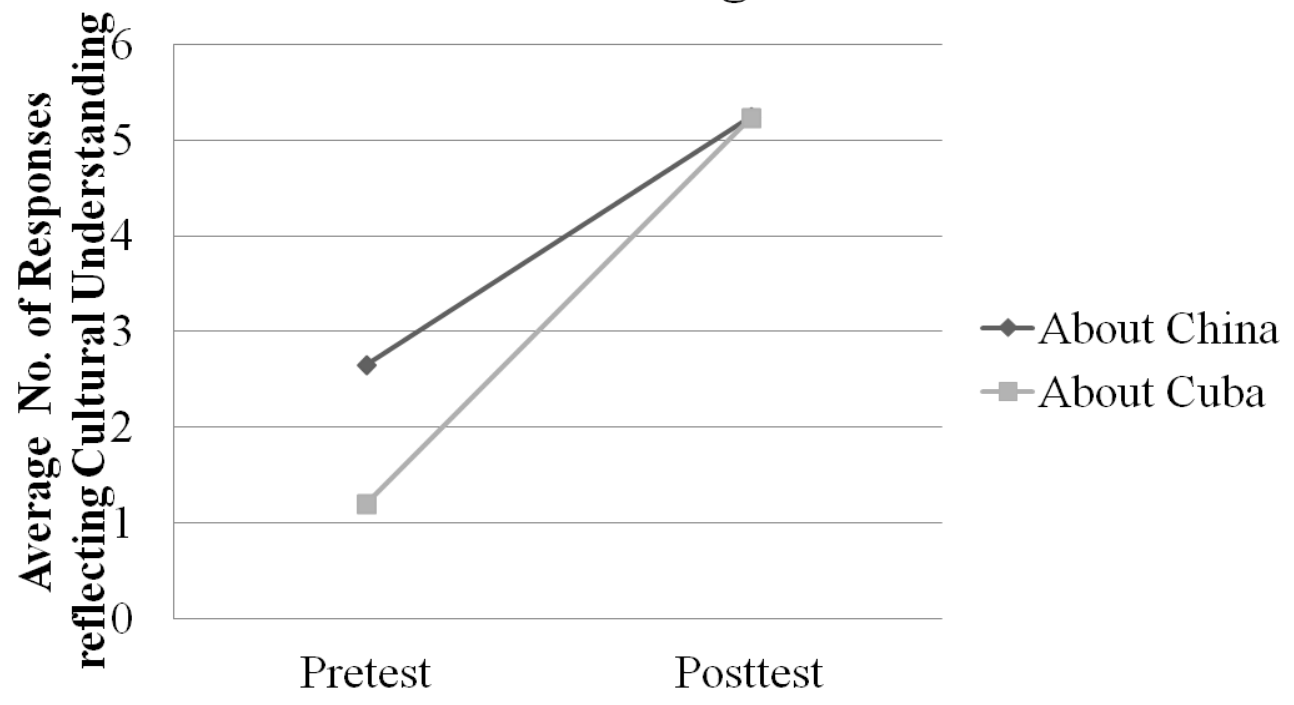

Figure 1. Children's interview responses before and after the programme

\section{Children's Interview Responses at the 4 Levels of Cultural Understanding}

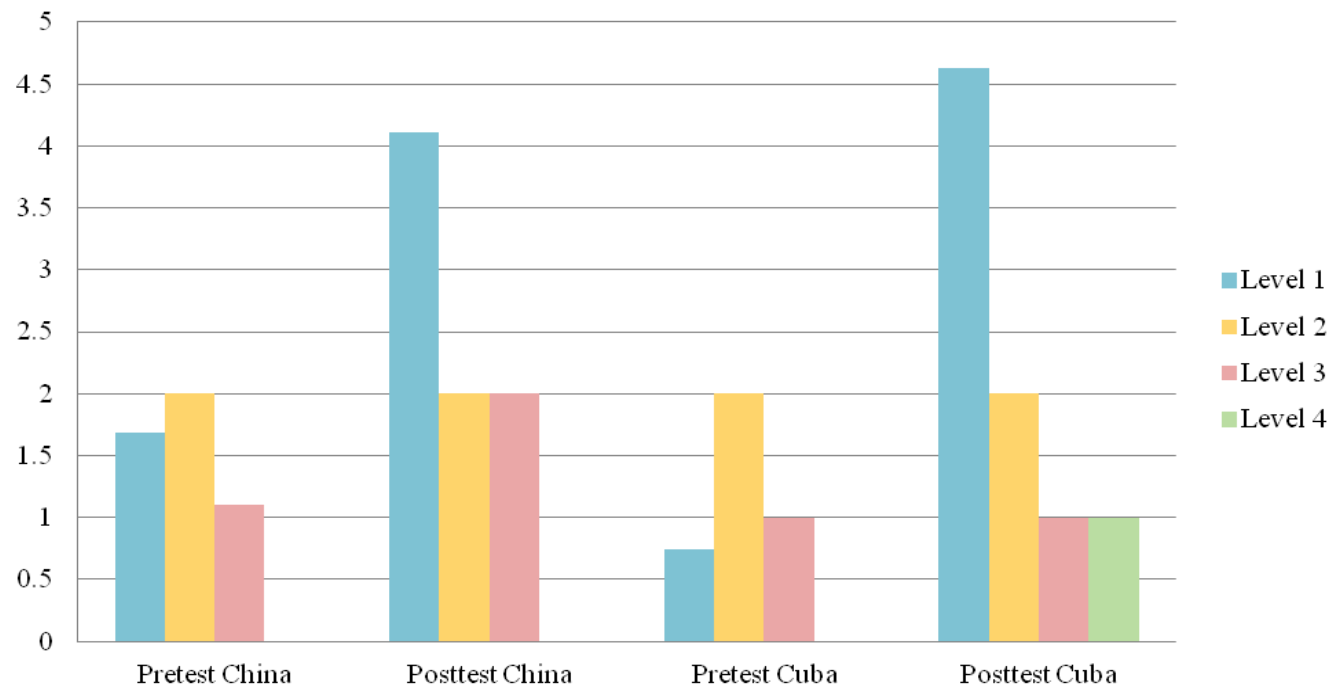

Figure 2. Children's interview responses at the four levels of cultural understanding 
Table 2

One-Way Analysis of Variance of Grade effects on children's interview responses on Cuba

\begin{tabular}{llllll}
\hline Source & $d f$ & $S S$ & $M S$ & $F$ & $p$ \\
\hline $\begin{array}{l}\text { Between } \\
\text { groups }\end{array}$ & 1 & 43.6 & 43.61 & 4.001 & $0.0489^{*}$ \\
$\begin{array}{l}\text { Within } \\
\text { groups }\end{array}$ & 80 & 871.9 & 10.90 & & \\
Total & 81 & 915.5 & & & \\
\hline Note. $*=p \leq .05$ & & & & \\
\end{tabular}

Table 3

One-Way Analysis of Variance of Class effects on children's interview responses on Cuba

\begin{tabular}{llllll}
\hline Source & $d f$ & $S S$ & $M S$ & $F$ & $p$ \\
\hline $\begin{array}{l}\text { Between } \\
\text { groups }\end{array}$ & 7 & 168.5 & 24.07 & 2.384 & $0.0296^{*}$ \\
$\begin{array}{l}\text { Within } \\
\text { groups }\end{array}$ & 74 & 747.1 & 10.10 & & \\
Total & 81 & 687.5 & & & \\
\hline
\end{tabular}

Note. ${ }^{*}=p \leq .05$ 


\section{Class Differences in Children's Interview Responses on Cuba before and after the Program}

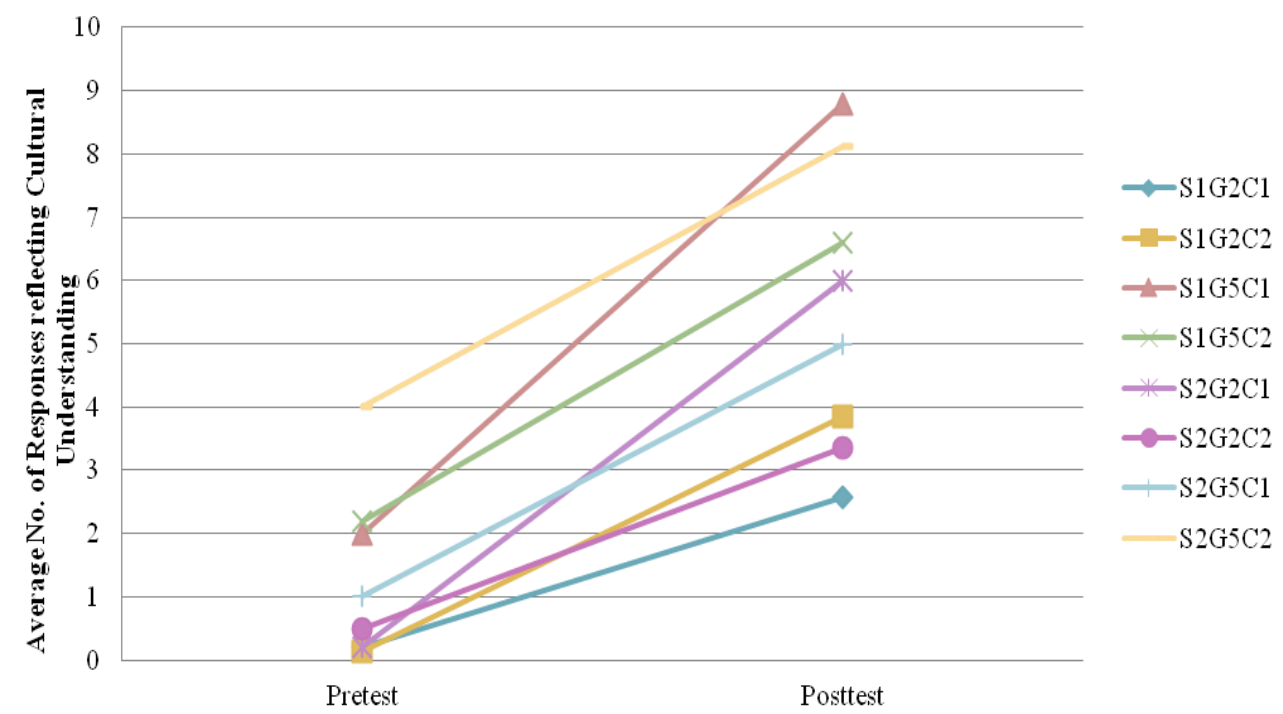

Figure 3. Class differences in children's interview responses on Cuba before and after the programme

\section{Discussion}

\section{Multicultural Music Programme can Increase Children's Cultural Understanding}

From the results, it is clear that children have increased their cultural understanding on China and Cuba after the programme. The fact that children knew little about Cuba at the start of the project contributed to the higher gain in their responses about Cuba than China at the end of the project (see Figure 1). Indeed, as I was conducting the pre-test interviews, I was surprised to observe how much children had already learned about China through the media, friends who are Chinese, and the popular Chinese restaurants that are everywhere in New Jersey (and many places in the world too!). On the other hand, a lot of the children could not tell me anything about Cuba before the programme even though there were many Cubans living in the area. Moreover, contrary to my expectation, even children who were immigrants from other countries in South America knew more about China than Cuba at the start of the study. This showed that it was actually important to introduce Cuban music and culture to the children there.

The increase in cultural understanding among the children was further supported by the fact that there were a lot more children who could not provide any answer before the programme than after the programme. It accounted for $15 \%$ versus $1 \%$ of the participating children for their responses on China and $56 \%$ versus $3 \%$ of the 
children for their responses on Cuba before and after the programme respectively. This phenomenon is particularly obvious among the responses on Cuba. Furthermore, after the project, there were much more responses relating to singing, dancing and languages which were important topics of the programme. Thus, children's learning from the programme has been demonstrated.

From an analysis of the interview data, it was found that the stereotype responses of the two cultures were evident before the programme and they were replaced by more realistic and true concepts of the cultures at the end of the programme. Examples of the stereotype responses that were recorded from the interviews before the programme include:

All of them look the same (China)

Some people are dangerous in China because they like fighting (China)

They are black (Cuba)

These responses were such a contrast to the responses collected afterwards:

I learned what Chinese people look like. They look different, not the same. (China)

People from different places came there, example, African people. (Cuba)

Therefore, these data suggested that those students have probably moved away from an ethnocentric/-biased view towards Chinese and Cuban cultures.

Interestingly, such increase was not affected by children's ages, gender and learning needs. In other words, the $2^{\text {nd }}$ and $5^{\text {th }}$ graders; boys and girls; the bilingual, learning disabled, and typical children all demonstrated an increase in cultural understanding. This does not support the findings of the strong age factor in the study of Sousa et al (2005). Such difference can probably be accounted for by the differences in methodology. Sousa et al used a standardised psychological test to assess attitude towards other people whereas the present study used open-ended interview to assess cultural understanding. It is possible that children of younger ages may find it easier to express their opinion through verbal interviews than written questionnaires, or vice versa. Another possible explanation is that those Portuguese children at ages 7-10 in Sousa et al.'s study may respond more differently than the $2^{\text {nd }}$ (7-8 years) and $5^{\text {th }}(10-11$ years) grade American children of this study. Further studies where children of the same age range from specific cultures responding to both interviews and questionnaires will be needed to provide insight into the age factor.

The class differences that were significant with Cuban data need to be further examined (Figure 3). Reflecting on my observations during the lessons, it becomes clear that the class differences are closely related to children's learning attitude. A pattern can be observed in which the more positive and well behaved the classroom atmosphere, the higher the gains in cultural understanding. For instance, among the eight classes, the highest gains in cultural understanding of Cuba occurred among the class of $5^{\text {th }}$ graders, which was a well-behaved class with children being very eager to learn. The students in this class could recall the whole Chinese song all by themselves without my help just one week after I taught them. On the other hand, the $2^{\text {nd }}$ grade class, which showed the 
lowest gains in cultural understanding of Cuba, was a class where the children got easily distracted and overexcited. Classroom management was quite an issue in this class, though these children were also motivated to learn. Not to say my research assistant who has less teaching experience, even I found it quite a challenge to teach this class. Therefore, students' learning attitude is an influential factor that can affect the extent to which they increase their cultural understanding.

Teachers need to build a good learning attitude among the children to maximise cultural understanding. In this study, it has been observed that musical activities provided an enjoyable and pleasant experience for children in their learning of music and cultures, and that in turn promoted more positive responses. Therefore, the inclusion of music into the multicultural programme can provide a strong motivational force in developing cultural understanding.

\section{Toward a High Level of Cultural Understanding}

As seen in Figure 2, it seems to be easy to increase the cultural knowledge, that is the first level of cultural understanding. Yet for the other higher levels of understanding, it is much harder to develop among the children within a six-week period.

Here are some examples of responses collected under each of the four levels of cultural understanding:

Table 4

Examples of interview data collected across the four levels of cultural understanding

\begin{tabular}{|l|l|l|}
\hline Level & Example & Justification \\
\hline Level 1 Knowledge & They eat Chinese food. (China) & factual information \\
\hline Level 2 Awareness & $\begin{array}{l}\text { Their instrument is different from } \\
\text { those in the US. (Cuba) }\end{array}$ & comparison \\
\hline Level 3 Sensitivity & It's an important culture. (China) & $\begin{array}{l}\text { expression of } \\
\text { feelings }\end{array}$ \\
\hline Level 4 Valuing & $\begin{array}{l}\text { People who sing the music, they're } \\
\text { not shy, they're not afraid if people } \\
\text { laugh at them. I like that. For } \\
\text { example, when I am short, they } \\
\text { laugh at me. I like that. I'm not } \\
\text { afraid of it anymore. (Cuba) }\end{array}$ & $\begin{array}{l}\text { unbiased view, } \\
\text { global awareness }\end{array}$ \\
\hline
\end{tabular}

The words from this student who demonstrated Level 4 Valuing showed that the high level of cultural understanding is something precious that educators want to see in their classroom. The findings of this study regarding the limited amount of high levels of cultural understanding among the children echo with the findings of Nam (2007), who felt that an in-depth study of few cultures would do a better job in promoting high 
level of cultural understanding than a superficial study of many cultures. Further research providing a programme with a more extended period of time without studying too many cultures is needed to confirm this relationship.

\section{Measurement of Cultural Understanding}

It is a challenge to measure cultural understanding. It is an abstract construct that cannot be easily observed or measured. The present study used Edwards' (1994) four level of cultural understanding as a reference point to assess children's cultural understanding. It has shown to be a useful research assessment tool. While organising the interview data into four levels, it helps to organise the data without which it becomes impossible to determine objectively the extent of understanding. Moreover, the concept of cultural understanding as a continuum that ranges from biased to unbiased view is helpful in showing the degree of understanding so that we can place the data collected accordingly, which in turn can allow for comparison and analysis.

I found it very useful to use the quantitative data as the basis to indicate the amount and direction of changes. Through the words of the children, I was able to tap into their thinking to a certain extent that provided further insight into those numbers. Therefore, the qualitative data can provide meaning and explanations to the information indicated by the quantitative data and both qualitative and quantitative data together give us a more complete picture of children' learning and development of cultural understanding.

\section{Children are Motivated to Learn about World Musics and Cultures}

In this study, the two researchers served the roles of both the teacher and researcher. The first-hand teaching experiences during the study were most gratifying. It was evident from the observations that the teaching materials on Chinese and Cuban music and cultures brought novelty, interest and challenges that motivate children learning. Children asked a lot of questions out of curiosity. After each activity, they often asked: "Can we do that again?" Such positive responses were also evident from my previous studies (Chen-Hafteck, 2007b; 2010). It is clear that music has provided the motivation to learn. Multicultural programme without music cannot be the same. Music activities can vivify and humanise the social studies class that might otherwise become a dry recitation of dates and facts (Rosenbloom, 2004).

It is interesting to note the level of engagement of the children during the study. Some children came to me at my second lesson, speaking some Chinese that they learned by themselves from a library book that they took out from their own initiatives following my first lesson. It was amazing to see how the children from the 'Learning Disabled' class who were considered having difficulty in paying attention showed themselves to be absolutely focused during the meditation activity to Chinese music. The classroom teacher who was present at that time was surprised and thrilled. She told me afterwards that she could not believe her eyes. In another classroom, we saw an African-American $5^{\text {th }}$ grade boy who was totally absorbed into a Chinese dance song, incorporating some hip-hop dance moves into his dance. At that moment, he showed that he felt the rhythm and beat of the Chinese song, and decided to express himself in 
his own personal way that originated from his culture. It should be noted that although I showed some basic moves that were authentic to the Chinese dance for this song, I also allowed space for children to improvise their own moves. This particular student has combined both the Chinese moves and movement from his own culture. It then became his new interpretation of the music through movement. Therefore, I would consider this as an example of cultural understanding, which is superior to what some other students who just copied what I did.

\section{Conclusion}

Multicultural music education can increase the cultural understanding of unfamiliar cultures among elementary children, across different ages, language backgrounds and learning abilities. Acquiring basic level of understanding (knowledge) can easily be achieved, but not so much for higher levels (awareness, sensitivity \& valuing). Therefore, music educators need to be aware of such challenge and try to facilitate children's development of high level of cultural understanding.

Introducing multicultural music in classroom can be an excellent educational experience for students. It can serve important educational goal of increasing cultural understanding, motivate student learning and provide an interdisciplinary education to students through integrating the study of music and culture or social studies. Therefore, it is recommended that multicultural music education should be promoted more widely in the classroom.

\section{Acknowledgement}

I would like to acknowledge the support of the project's research assistants, Monica Fontaine and Jenna Cipolla. Special thanks are also due to Dr. David Joiner at Kean University for his kind assistance with the statistical analyses of the data.

\section{References}

Abril, C. R. (2006) Learning outcomes of two approaches to multicultural music education, International Journal of Music Education, 24, 30-42.

Chen-Hafteck, L. (2007a). Contextual analyses of children's responses to an integrated Chinese music and culture experience. Music Education Research, 9, 3, 337353.

Chen-Hafteck, L. (2007b). In search of a motivating multicultural music experience: lessons learned from the sounds of silk project. International Journal of Music Education, 25, 3, 223-233.

Chen-Hafteck, L. (2010). Discovering world music and children's worlds - pedagogy responding to children's learning needs. In A. C. Clements (Ed.), Alternative approaches in music education: Case studies from the field (pp. 41-55). Lanham, MD: Rowman \& Littlefield. 
Banks, J. A. (2004). Multicultural education: Historical development, dimensions, and practices. In J. A. Banks \& C. A. McGee Banks (Eds.). Handbook of research on multicultural education (2nd ed., pp. 3-29). San Francisco, CA: JosseyBass.

Campbell, P. S. \& Scott-Kassner, C. (2007). Music in childhood: From preschool through the elementary grades (3rd ed.) Belmont, CA: Thomson Schirmer.

Clarke, E., DeNora, T. \& Vuoskoski, J. (2015). Music, empathy and cultural understanding. Physics of Life Reviews, 15, 61-88.

Edwards, K. L. (1994). North American Indian music instruction: Influences upon attitudes, cultural perceptions, and achievement. Doctoral dissertation, Arizona State University, Tempe, 1994. Dissertation Abstracts International, 56, 130.

Elliott, D. J. (1989). Key concepts in multicultural music education. International Journal of Music Education, (1), 11-18.

Gay, G. (2010). Culturally responsive teaching: Theory, research, and practice. New York, NY: Teachers College Press.

Gay, G., Dingus, J.E. \& Jackson, C. W. (2003, July). The presence and performance of teachers of color in the profession. Unpublished report prepared for the National Collaborative on Diversity in the Teaching Force. Washington D.C.

Gorski, P. (2008). The myth of the culture of poverty. Poverty and Learning, 65(7), 3235.

Ilari, B. et al (2013). Singing and cultural understanding: A music education perspective. International Journal of Music Education, 31(2), 202-216.

Ingersoll, R., Merrill, L. \& Stuckey, D. (2014). Seven trends: The transformation of the teaching force. CPRE Report (\#RR-80). Philadelphia, PN: Consortium for Policy Research in Education, University of Pennsylvania.

Kirschner, S. \& Tomasello, M. (2010). Joint music making promotes prosocial behaviour in 4-year-old children. Evolution and Human Behaviour, 31, 354364.

Ladson-Billings, G. (2004). New directions in multicultural education. Complexities, boundaries, and critical race theory. In J.A. Banks \& C.A.M. Banks (Eds.). Handbook of research on multicultural education (pp. 145-166). New York, NY: MacMillan.

Legette, R. M. (2003). Multicultural music education attitudes, values, and practices of public school music teachers. Journal of Music Teacher Education, 13(1), 5159.

Nam, I. (2007). Children's perceptions about, attitudes toward, and understandings of multicultural music education. Unpublished doctoral dissertation. Arizona State University, USA. UMI No. 3287989.

Rosenbloom, A.F. (2004). High school music studies and social studies: an interdisciplinary approach. Music Educators Journal, 90 (3), 41-45.

Soland, J., Hamilton, L.S. \& Stecher, B.M. (2013). Measuring $21^{\text {st }}$ century competencies: Guidance for educators. RAND Corporation/ Asia Society/ Global Cities Education Network.

Sousa, M.R., Neto, F. \& Mullet, E. (2005). Can music change ethnic attitudes among children? Psychology of Music, 33(3), 304-316. 
Tu, M. (2009). The effects of a Chinese music curriculum on cultural attitudes, tonal discrimination, singing accuracy, and acquisition of Chinese lyrics for third-, fourth-, and fifth-grade students. (Doctoral dissertation). Retrieved from ProQuest, UMI Dissertations Publishing (Accession Order No. 3392598).

Vavrus, M. (2002). Transforming the multicultural education of teachers: Theory, research and practice. New York, NY: Teachers College Press.

\section{Biography}

Lily Chen-Hafteck is professor of Music Education and Chair of faculty at UCLA Herb Alpert School of Music. She is a Fulbright scholar who holds a Ph.D. from University of Reading, U.K. and received postdoctoral research fellowship at University of Pretoria, South Africa and University of Surrey Roehampton, U.K. She has held leadership positions of International Society for Music Education (ISME) as member of its 'Board of Directors', chair of its 'Young Professionals Focus Group and Early Childhood Commission'; served as the 'Eastern Division Representative' of the Early Childhood Special Research Interest Group, National Association for Music Education (NAfME) and World Music Representative of California Music Educators Association (CMEA). She is the founder of the 'Educating the Creative Mind' project, funded by National Endowment for the Arts; and a co-investigator of 'Advancing Interdisciplinary Research in Singing' (AIRS) project, funded by the Social Sciences and Humanities Research Council (SSHRC) of Canada. 